\title{
Perinatal fluoxetine increases hippocampal neurogenesis and reverses the lasting effects of pre-gestational stress on serum corticosterone, but not on maternal behavior, in the rat dam
}

\author{
Mary Gemmel $^{\mathrm{a}}$, Danny Harmeyer ${ }^{\mathrm{a}}$, Eszter Bögi ${ }^{\mathrm{b}}$, Marianne Fillet $^{\mathrm{c}}$, Lesley A. Hill ${ }^{\mathrm{d}}$, \\ Geoffrey L. Hammond ${ }^{\text {d, Thierry D. Charlier }}{ }^{\mathrm{e}}$, Jodi L. Pawluski ${ }^{\mathrm{e}, *}$ \\ a Department of Biological Sciences, Ohio University, Athens, OH, USA \\ ${ }^{\mathbf{b}}$ Institute of Experimental Pharmacology and Toxicology, Slovak Academy of Sciences, Department of Reproductive Toxicology, Bratislava, Slovak Republic \\ ${ }^{\mathrm{c}}$ Laboratory for the Analysis of Medicines (LAM), Department of Pharmacy, CIRM, University of Liege, CHU, Liege, Belgium \\ ${ }^{\mathrm{d}}$ Department of Cellular and Physiological Sciences, Faculty of Medicine, The University of British Columbia, Vancouver, Canada \\ ${ }^{\mathrm{e}}$ Institut de Recherche en Sante, Environnement et Travail (Irset), Institut National de la Santé et de la Recherche Médicale U1085, Université de Rennes 1, Rennes, France
}

\section{A R T I C L E I N F O}

\section{Keywords:}

Depression

Neuroplasticity

SSRI

Anxiety

Reproduction

Corticosteroid binding globulin

\begin{abstract}
A B S T R A C T
There is increasing evidence that mental health concerns, stress-related mental illnesses, and parental stress prior to conception have long-term effects on offspring outcomes. However, more work is needed to understand how pre-gestational stress might affect neurobehavioral outcomes in the mother. We investigated how chronic stress prior to gestation affects maternal behavior and related physiology, and aimed to determine the role that perinatal SSRIs have in altering these stress effects. To do this, female Sprague-Dawley rats were subject to chronic unpredictable stress (CUS) prior to breeding. During the perinatal period they were administered fluoxetine $(10 \mathrm{mg} / \mathrm{kg} /$ day). Four groups of dams were studied: Control + Vehicle, Pre-gestational Stress + Vehicle, Control + Fluoxetine and Pre-gestational Stress + Fluoxetine. Maternal weight, breeding success, and maternal caregiving behaviors were recorded. Measures of serum corticosterone and corticosteroid-binging globulin (CBG) and the number of immature neurons in the dorsal hippocampus were also assessed in the late postpartum. Main findings show pre-gestational stress resulted in poor reproductive success and maintenance of pregnancy. Pre-gestationally stressed dams also showed higher levels of nursing and fewer bouts of licking/ grooming offspring in the first week postpartum - behaviors that were not reversed by perinatal fluoxetine treatment. In the dam, perinatal fluoxetine treatment reversed the effect of pre-gestational maternal stress on serum corticosterone levels and increased serum CBG levels as well as neurogenesis in the dorsal hippocampus. Maternal corticosterone levels significantly correlated with blanket and passive nursing. This work provides evidence for a long-term impact of stress prior to gestation in the mother, and shows that perinatal SSRI medications can prevent some of these effects.
\end{abstract}

\section{Introduction}

Up to $20 \%$ of women experience a stress-related disorder, such as depression or anxiety, during the perinatal period, yet our understanding of how maternal stress and mental illness affect the maternal brain and maternal behavior is far from complete. Importantly, there is a need to determine how maternal outcomes are affected by stress prior to gestation as stress is an associated risk factor for maternal mental illness during the perinatal period [1]. We know that maternal stress effects are transmitted across generations, particularly when stress occurs during the perinatal period [2,3]. However, little is known about how pre-gestational stress affects neurobehavioral outcomes in the mother. One study has shown that pre-gestational stress can increase anhedonia as well as serum corticosterone and corticosterone-releasing hormone levels during late pregnancy [4]. Assessment of additional maternal outcomes, such as maternal care, as well as central measures of neuroplasticity, are needed to further understand the long-term effect of pre-gestational stress on the mother.

Of particular importance is the effect of maternal stress on maternal caregiving behaviors that may have a long-term effect on offspring outcomes. Stressed, depressed, and anxious mothers respond more negatively to their infants compared with healthy mothers [5-7].

\footnotetext{
* Corresponding author at: IRSET-INSERM U1085, Université de Rennes 1, Campus Villejean, 9 avenue du Prof. Leon Bernard, 35000 Rennes, France.

E-mail addresses: j.pawluski@gmail.com, Jodi-lynn.pawluski@univ-rennes1.fr (J.L. Pawluski).
} 
Perinatal depression and anxiety also reduces synchrony between mother and infant by reducing vocal and visual communications, touching, and smiling $[5,6]$. Alterations in maternal caregiving behaviors after repeated maternal stress, or exogenous administration of glucocorticoids, occur in rodent models. Dams stressed during gestation spend less time licking and grooming offspring and often more time nursing offspring [8-12] and dams receiving postpartum corticosterone treatment spend less time nursing offspring [8]. However, the effects of pregestational stress on maternal-caregiving remain to be explored.

Maternal stress and stress-related disorders can also affect the neurobiology of the mother. Clinical work shows changes in many brain areas of women with affective symptoms and postpartum depression [13], and these changes are often unique from depression outside of the perinatal period [1]. Animal models are beginning to show that maternal stress can remodel the maternal brain. Repeated restraint stress during pregnancy, or exogenous corticosterone administration, alters hippocampal neurogenesis, dendritic morphology, and other measures of plasticity in the maternal rodent brain during pregnancy and the postpartum period [11,14-20]. Gestational stress can also abolish the enduring increase in hippocampal LTP months after giving birth, suggesting a long-term impact of stress exposure on the maternal brain [21]. More work is needed to understand how maternal stress, prior to conception, influences hippocampal outcomes; as the hippocampus, and neurogenesis in this brain area, plays a critical role in emotion, stress, anxiety, and depression [22-24], as well as maternal experience [25-28].

Many women are prescribed selective serotonin reuptake inhibitor medications (SSRIs) during the perinatal period to treat stress-related affective disorders. Prescription estimates for treatment of perinatal affective disorders with SSRIs range from 4 to $10 \%$ of pregnant women in developed countries [2,29-32]. These drugs act to alleviate depressive symptoms in adults by normalizing serotonin function, regulating the HPA axis [33], and altering hippocampal plasticity [34,35]. During the perinatal period, SSRIs may also affect maternal care-giving behaviors and maternal brain plasticity. Clinical work shows that when controlling for the effects of maternal depression, mothers treated with an SSRI during pregnancy interrupt their child more during play [36]. Others show that effective antidepressant treatment improves gratification in the maternal role but not maternal-infant interaction in women with Postpartum Depression (PPD) [37], while others show no effects of antidepressant medications on maternal feelings of attachment [38]. In rodent models, gestational SSRI treatment increases the frequency of maternal licking of offspring, and in low doses, increases the duration of crouching over offspring [39]. This is also evident with postpartum SSRI treatment which increases arch-back nursing behaviors, reduces maternal self-grooming, and reverses the effects of high corticosterone levels on maternal care-giving behaviors [40,41]. Recent work also shows significant changes in hippocampal plasticity in the maternal brain in response to SSRI treatment; SSRIs increase neurogenesis in the maternal hippocampus [41] and decrease both global measures of methylation in the dentate gyrus and serotonin metabolism in the hippocampus of the mother [42]. Thus, emerging evidence points to potential long-term effects of SSRIs on the brain and behavior of the mother.

Our aim was to investigate how chronic stress prior to gestation affects maternal behavior, related physiology, and neuroplasticity, and to determine how perinatal SSRI treatment with fluoxetine, one of the most popular SSRIs, might alter these stress effects in the mother. It was expected that both pre-gestational stress and perinatal SSRI treatment would have enduring effects on neurobehavioral outcomes in the mother, particularly those of maternal care-giving behaviors and neurogenesis, with SSRIs preventing the effects of maternal stress on these measures in the mother.

\section{Material and methods}

\subsection{Animals}

Thirty-four adult female Sprague-Dawley rats (175-199 g, approximately 60 days of age) and 9 adult male Sprague-Dawley rats (275-299 g) were purchased from Harlan Laboratories Inc. (Indianapolis, Indiana). Animals were kept under standard laboratory conditions in a 12:12-h light/dark schedule and rats were initially housed in same-sex pairs in clear polyurethane bins with basic enrichment and ad libitum access to rat chow and tap water. Experiments were approved by the Institutional Animal Care and Use Committee (IACUC, 12-H-053, 14-H-011).

As maternal stress in rodents can induce aspects of anxiety and depressive-like behavior, a model of chronic unpredictable stress (CUS) was utilized in the present study based on previous work $[4,43]$. Prior to breeding, females were randomly assigned to stress or control groups (16 control, 18 stress). Female rats in the control group were pairhoused and those in the stress group were individually housed and subjected to CUS for 3 weeks. Single housing was part of the stress procedure as single housing alone can induce depressive-like behavior in female mice [44]. The CUS consisted of $0-2$ stressors per day for 3 weeks prior to breeding. Stressors included restraint under bright light for $1 \mathrm{~h}$; $24 \mathrm{~h}$ overcrowding; overnight exposure to damp bedding; $12 \mathrm{~h}$ food deprivation; $5 \mathrm{~min}$ of forced swimming or cage rotation for $12 \mathrm{~h}$. Females were weighed weekly during the stressing procedure, and percent weight gain was calculated. After CUS, all females were subject to behavioral testing to assess the effects of stress on anxiety and working memory (both of which are associated with depressive-like behavior). Fluoxetine or vehicle treatment began during gestation and lasted until sacrifice, resulting in 4 groups of dams: Control + Vehicle $(\mathrm{CV}, \mathrm{n}=8$ ), Pre-gestational Stress + Vehicle (PGSV, $\mathrm{n}=9$ ), Control + Fluoxetine (CF, $\mathrm{n}=8)$ and Pre-gestational Stress + Fluoxetine (PGSF, $\mathrm{n}=9$ ). See Fig. 1 for a timeline of the study. Unfortunately, due to unexpected pregnancy loss (see below and Fig. 2), particularly in the stressed females, group sizes were lower with $\mathrm{n}=5-8$ /group $(\mathrm{CV}=6$, $\mathrm{CF}=7, \mathrm{PGSV}=5, \mathrm{PGSF}=5$ ).

\subsection{CUS effects on weight, exploration, and memory in females prior to breeding}

Female weight across CUS, activity in an open field, as an indicator of anxiety-like behavior and working memory performance after stress, as a measure of working memory deficits associated with depression [45] were measured prior to breading as described [46-48]. The day prior to testing, each female was habituated to a darkened polyurethane apparatus $(50 \mathrm{~cm} \times 50 \mathrm{~cm} \times 50 \mathrm{~cm})$, which served as an open field test, for $15 \mathrm{~min}$. Anymaze Behavioral Tracking Software (Stoelting Europe, Ireland) was used to calculate freezing episodes as an indicator of anxiety-like behaviors as well as distance moved in the periphery and center of the arena.

Twenty-four hours later, the ORT test began, and each female was put into the arena with two identical objects that were placed in opposite corners of the arena floor. Each female was allowed to explore the objects for a $10 \mathrm{~min}$ familiarization period. After a one hour delay, each female was again placed in the same arena for $5 \mathrm{~min}$ but one object was replaced with a novel object in the same location. Twentyfour hours later females were tested again in the same way with one original object and one novel object. Time spent investigating each object and time with the novel, versus familiar, object was calculated as a percent. For object novel recognition memory, novel object exploration time was calculated as novel exploration/(novel + familiar exploration)*100 at the $1 \mathrm{~h}$ and $24 \mathrm{~h}$ period. Percentage of total time 


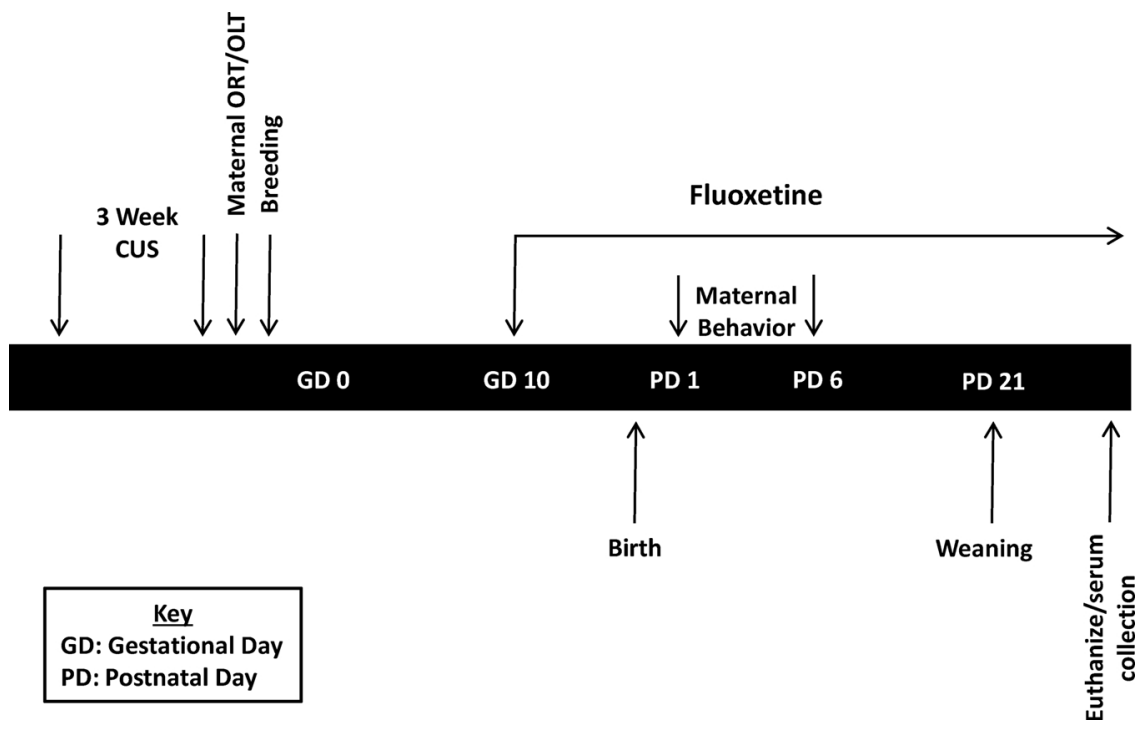

Fig. 1. Timeline of the study.

investigating the novel and familiar objects were also determined at each testing point ( $1 \mathrm{~h}$ and $24 \mathrm{~h}$ delays). One hour after the last ORT, OLT was completed for $5 \mathrm{~min}$ in which one of the objects in the previous trial was moved to a different location in the arena. For OLT, novel object exploration time was calculated as novel place exploration/(novel + familiar place exploration)*100. Objects were made from Lego ${ }^{\circ}$ and were counterbalanced between groups to ensure that the same object was not the familiar object for all females. Objects and arena were wiped clean with $70 \%$ ethanol between animals. Anymaze Behavioral Tracking Software (Stoelting Europe, Ireland) was used to calculate freezing episodes and distance moved during ORT and OLT. An observer blind to conditions recorded the time an animal spent exploring objects (i.e. sniffing/touching). Vaginal smears were collected after testing to control for estrous cycle effects as described [15].

\subsection{Breeding}

The day after behavioral testing, one female and one male were paired and pregnancy was determined with evidence of sperm in the vagina, accessed via a vaginal smear. This was identified as gestation day (GD) 1 and all dams were individually housed at this time. Dams were 12-14 weeks old at breeding, and each male was used to mate separately with up to 5 females. Males were randomly paired with females. Ten females were not able to maintain a viable pregnancy, even with rebreeding (max 3 times sperm was evident), leaving 14 control females and 10 stress females (see results for statistical details). All females were weighed on gestation day 7 and a $10 \%$ weight gain was indicative of pregnancy. A negligible weight gain on gestation day 7 , was an indicator that the female was not pregnant. Dams were weighed
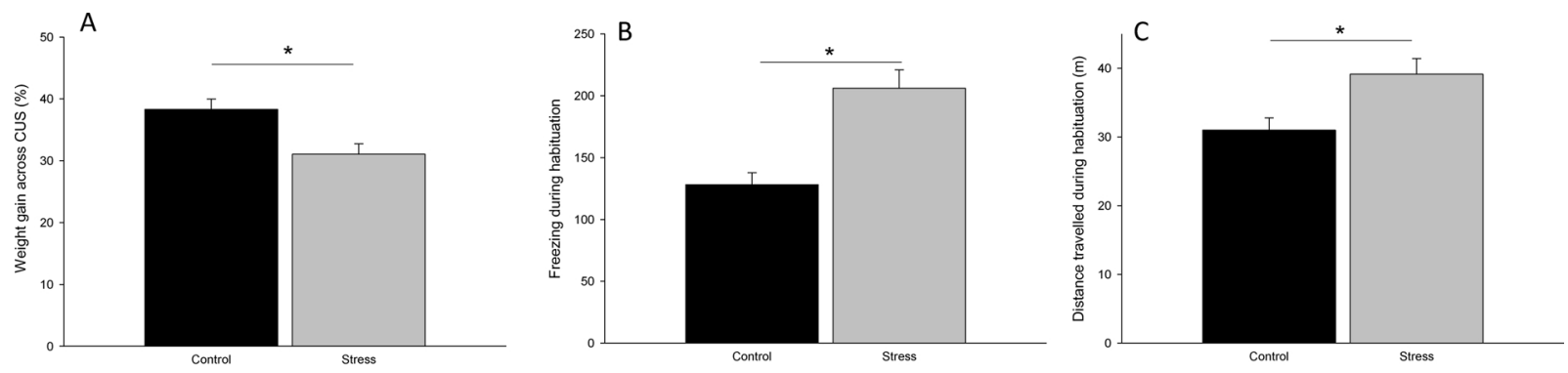

D
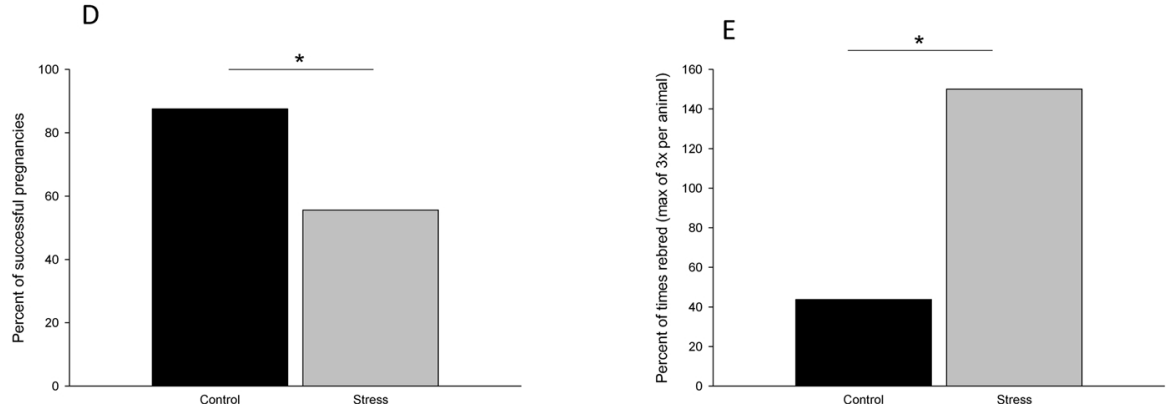

Fig. 2. Mean ( \pm SEM) A) weight gaining during CUS B) time freezing (s) during habituation and C) distance travelled (m) during ORT/OLT testing prior to breeding in control and stressed females. D) Number of successful pregnancies and E) number of times rebred in control and stressed females prior to treatment. Stress significantly A) decreased weight gain $(p=0.005), B)$ increased time freezing $(p=0.0004), C)$ increased distance traveled $(p=0.009)$, D) decreased successful pregnancies $(p=0.04)$, and $E)$ increased re-breeding attempts $(\mathrm{p}=0.01)$. *denotes significantly different. ( $\mathrm{n}=16-18 /$ group $)$. 
weekly during gestation and lactation. Weight gain was calculated from these dates. After weaning offspring were used for additional studies [49].

\subsection{Fluoxetine administration}

To acclimate females to eating the biscuit, a piece of wafer biscuit was given to dams on GD 8 and 9 prior to drug or vehicle administration as previously described [50]. We chose to administer biscuits on GD8 to ensure that females were indeed pregnant, as evidenced by increased weight gain mentioned above. Oral administration of fluoxetine (Fagron, Belgium) or vehicle was administered via a wafer biscuit beginning on GD10 and continuing until weaning (postnatal day (PD) 21). The dams received a biscuit twice a day filled with $5 \mathrm{mg} / \mathrm{kg}$ of fluoxetine in vehicle or vehicle (saline) as described [50-52] until sacrifice. Using this method of fluoxetine administration we have reported detectable levels of fluoxetine and norfluoxetine (fluoxetine's active metabolite) in serum of lactating mothers and their suckling pups [51]. For further information on fluoxetine and norfluoxetine levels, see below.

\subsection{Maternal caregiving behaviors}

Maternal pup-directed behaviors were observed on PD1-PD6 two times per day for $5 \mathrm{~min}$ based on previous literature [41]. Observations took place in the morning (between 8:30 a.m. and 10:30 a.m.) and the afternoon (between 1:30 p.m. and 3:30 p.m.). Time and number of bouts in the following maternal behaviors were recorded: licking (licking/grooming, licking while on the nest); nursing (arched-back nursing, blanket nursing, and/or passive nursing); nest building and time off the pups. Differences between groups in maternal nursing and licking/grooming behaviors were assessed using both total time in these maternal behaviors as well as time spent in these behaviors during the first and the last 3 days of maternal care observations.

\subsection{Serum collection}

Within a week of weaning, dams were left in home cages until sacrifice at which point dams were deeply anesthetized with isofluorane and rapidly decapitated. Trunk blood was promptly taken for further analysis of fluoxetine, norfluoxetine, corticosterone, and CBG as described $[41,50,53]$. Blood samples were stored overnight at $4{ }^{\circ} \mathrm{C}$ and centrifuged at $10,000 \times g$ for $10 \mathrm{~min}$. Serum was collected and stored at $-80{ }^{\circ} \mathrm{C}$ until further analysis.

\subsection{Fluoxetine and norfluoxetine analysis}

To determine serum fluoxetine and norfluoxetine concentrations in dams, liquid chromatography coupled with mass spectrometry (LC-MS/ MS) was used as described $[41,50,51,54]$. The chromatographic separation was achieved using an Ultra High Capacity chip including a $500 \mathrm{~nL}$ trapping column and a $150 \mathrm{~mm} \times 75 \mu \mathrm{m}$ analytical column, both packed with a Zorbax 80SB $5 \mu \mathrm{m}$ C18 phase (Agilent Technologies) on a 1200 series LC-chip system (Agilent Technologies, Germany). The mobile phase was composed of H2O/FA (100:.1, v/v) (A) and ACN/ $\mathrm{H} 2 \mathrm{O} / \mathrm{FA}(90: 10: .1, \mathrm{v} / \mathrm{v} / \mathrm{v})$ (B) which were used in gradient elution mode. Mass spectrometric detection was carried out using a 6340 Ion Trap consisting of a nanoelectrospray ionization source operating in positive mode (Agilent Technologies, Waldbronn). An Oasis $\mu$ Elution MCX 96-well plate (Waters, UK) was used to prepare the samples for the analysis. All conditions were performed in duplicate and back-calculated using a calibration curve. Twenty-five $\mu \mathrm{L}$ of serum was needed per animal. Mean ( \pm SEM) medication levels for the dams at sacrifice were
$19.3 \pm 6.7 \mathrm{ng} / \mathrm{ml}$ for fluoxetine and $110.1 \pm 26.1 \mathrm{ng} / \mathrm{ml}$ for norfluoxetine ( $\mathrm{n}=13$ treated dams).

\subsection{Corticosterone}

Serum samples were run in duplicate using a RIA kit for rat corticosterone from MP Biomedicals (Corticosterone $\mathrm{I}^{125}$ for rats and mice, MP Biomedicals) [55]. The assay had a sensitivity of $7.7 \mathrm{ng}$. Average CV was less than $5 \%$. Serum corticosterone levels from two females were not included due to technical error at sacrifice. Corticosterone levels were taken at sacrifice and were not used as an indicator of basal corticosterone levels. Corticosterone levels were converted to nM for consistency with the CBG results below by using the equation ng/ $\mathrm{ml} * 3.46$.

\subsection{Corticosterone binding globulin (CBG) capacity}

For analysis, samples were diluted $1 / 1500$ and incubated at room temperature with dextran-coated charcoal (DCC) to remove endogenous steroids for $30 \mathrm{~min}$. Centrifugation was then used to sediment DCC, and $100 \mu \mathrm{l}$ aliquots were dispensed into duplicate tubes containing $\left[{ }^{3} \mathrm{H}\right]$ corticosterone (specific activity: $50 \mathrm{Ci} / \mathrm{mmol}$; ARC, St. Louis, MO, USA, final concentration $\sim 10 \mathrm{nM}$ ) and another tube containing $1 \mu \mathrm{M}$ cold corticosterone to evaluate non-specific binding. Samples were incubated for $1 \mathrm{~h}$ at room temperature, followed by $30 \mathrm{~min}$ in an ice water bath. To remove unbound steroids, tubes were incubated with ice-cold DCC for $10 \mathrm{~min}$, and then centrifuged at $1800 \times g$ for $10 \mathrm{~min}$ at $4 \mathrm{C}$. To account for the dissociation of $\left[{ }^{3} \mathrm{H}\right]$ corticosterone from CBG during the latter DCC separation step, a correction factor was used as described [56]. Supernatants were transferred into scintillation vials with $4 \mathrm{ml}$ of Aqueous Counting Scintillant (PerkinElmer, Waltham, MA, USA) to determine the CBG-bound $\left[{ }^{3} \mathrm{H}\right]$ corticosterone after subtracting non-specifically bound $\left[{ }^{3} \mathrm{H}\right]$ corticosterone which was then used to determine the corticosterone binding capacity of CBG in nM. Inter-assay variability was 5.1\%. Estimates of free corticosterone were computed with the equation total corticosterone (nM)*100/CBG(nM) (FCI - free corticosterone index) as previously described [57].

\subsection{Histology}

To verify how pre-gestational stress and chronic fluoxetine treatment affect neurogenesis in the maternal brain, hippocampal neurogenesis was assessed by looking at the number of doublecortin immunoreactive cells (DCX-ir; immature neurons) in the dorsal hippocampus. At sacrifice brains were immersion-fixed in $4 \%$ paraformaldehyde for $24 \mathrm{~h}$, cryoprotected in $30 \%$ sucrose/phosphate-buffered saline solution for up to 1 week, snap frozen, and kept at $-80^{\circ} \mathrm{C}$ until further use. Tissue was sliced in $40 \mu \mathrm{m}$ sections on a cryostat (Leica Biosystems, France) throughout the hippocampus in series of 10. Sections were stored in antifreeze solution and maintained at $-18^{\circ} \mathrm{C}$. One brain was lost in shipping. Partial eta squared $\left(\eta_{p}{ }^{2}\right)$ values have been indicated to ensure appropriate effect size.

For immunostaining, one series of tissue, from the 10 series, was used for doublecortin analysis. Tissue was rinsed between steps in PBS and PBST and was incubated in $0.6 \% \mathrm{H}_{2} \mathrm{O}_{2}$ for $30 \mathrm{~min}$, blocked in serum, and incubated overnight at $4{ }^{\circ} \mathrm{C}$ in goat anti-doublecortin (1:300, Santa Cruz Biotechnology, Dallas Texas, USA). Sections were incubated for $2 \mathrm{~h}$ at room temperature in biotinylated rabbit anti-goat (1:500, Jackson ImmunoResearch) and then for $1.5 \mathrm{~h}$ in avidine-biotine complex (ABC Elite kit; 1:1000; Vector laboratories, France). DAB (3,3diaminobenzidine; Vector laboratories, France) was used in the final step. Sections were mounted on Superfrost Plus slides (Fischer 
Scientific, Europe), dried, dehydrated and cover-slipped with Permount (Fischer Scientific, Europe).

For quantification, the numbers of DCX-ir cells were counted under $40 \times$ objective as described $[58,59]$. Cells were counted in the GCL/SGZ in the first 4 sections of the dorsal hippocampus on both sides of every 10th slice. Cells were considered DCX-ir if cell bodies were clearly stained and localized in the area of interest.

\subsection{Statistical analysis}

Data were analyzed using the software Statistica (Dell Inc.). Student $t$-tests were conducted on outcomes prior to breeding in stressed and non-stressed females (prior to treatment) on weight gain during CUS and behaviors in the ORT/OLT task with condition (stress/control) as the independent factor. Chi-square tests were done on pregnancy rate and rebreeding rate in stressed and control females, prior to treatment. In dams, ANOVAs were run on litter characteristics, time in maternal caregiving behaviors, weight change during lactation, corticosterone, corticosteroid binding globulin (CBG), and number of immature neurons in the GCL with condition (stress/control) and treatment (fluoxetine/vehicle) as independent factors. Significant interaction effects were analyzed in more detail by a Fisher LSD post hoc test. Pearson correlations were run between corticosterone levels, maternal behaviors and number of immature neurons in the GCL. A priori we expected significant effects of pre-gestational stress on maternal measures of pupdirected care $[12,60]$, thus further analyses were carried out on stressed and non-stressed females not exposed to fluoxetine. Analysis of covariance tests were also done on estrous cycle phase during ORT/OLT, age at conception on maternal outcomes, and days past weaning, where appropriate. Significance was set at $p<0.05$.

\section{Results}

\subsection{Verification of stress procedure prior to breeding}

Stressed females gained significantly less weight during the three weeks of CUS ( $t=3.05$, df $=31, p=0.005$; Fig. 2A). Stressed females had significantly more freezing episodes during habituation in an open field $(\mathrm{t}=-4.31, \mathrm{df}=31, \mathrm{p}=0.0002$, Fig. $2 \mathrm{~B})$ and traveled more distance in the open field ( $\mathrm{t}=2.79$, $\mathrm{df}=31, \mathrm{p}=0.009$ ) compared to control females (Fig. 2C). Increase distance was due to significant increase in distance moved in the periphery of the arena, not the central portion $(\mathrm{t}=2.89$, $\mathrm{df}=31, \mathrm{p}=0.007)$. In the ORT and OLT tests, stressed females had significantly more freezing episodes than controls (p's $<0.003$; Table 1). Total time exploring the objects was significantly different between groups during the ORT $24 \mathrm{~h}$ delay and OLT test with stressed females spending significantly more time exploring objects overall (ORT $24 \mathrm{~h}: \mathrm{t}=-2.53, \mathrm{df}=30, \mathrm{p}=0.02$, Table 1, OLT:

Table 1

Mean ( \pm SEM) measures on the ORT at $1 \mathrm{~h}$ and $24 \mathrm{~h}$, and on OLT prior to breeding in stressed and control female rats.

\begin{tabular}{lll}
\hline & Control & Stress \\
\hline ORT 1h & & \\
$\quad$ Freezing episodes & $45.7 \pm 3.7$ & $75.7 \pm 5.3^{\mathrm{a}}$ \\
$\quad$ novel/(novel + familiar)(\%) & $41.5 \pm 5.8$ & $48.0 \pm 3.6$ \\
$\quad$ Total time exploring objects (s) & $24.6 \pm 9.4$ & $32.8 \pm 13.3$ \\
ORT 24h & & \\
$\quad$ Freezing episodes & $47.8 \pm 4.2$ & $77.8 \pm 4.5^{\mathrm{a}}$ \\
$\quad$ novel/(novel + familiar)(\%) & $51.0 \pm 5.3$ & $53.6 \pm 4.2$ \\
$\quad$ Total time exploring objects (s) & $19.2 \pm 11.4$ & $29.6 \pm 11.7^{\mathrm{a}}$ \\
OLT & & \\
$\quad$ Freezing (s) & $58.5 \pm 3.9$ & $148.5 \pm 21.7^{\mathrm{a}}$ \\
$\quad$ novel/(novel + familiar)(\%) & $52.2 \pm 5.7$ & $54.9 \pm 4.5$ \\
$\quad$ Total time exploring objects (s) & $19.8 \pm 11.9$ & $37.2 \pm 25.7^{\mathrm{a}}$ \\
\hline
\end{tabular}

a denotes significantly different. ( $\mathrm{n}=15-18$ /group).
Table 2

Mean ( \pm SEM) weight change during the postpartum (\%), litter weight on PD1 (g), and litter size. $\quad \mathrm{CV}=$ control + vehicle, $\quad \mathrm{PGSV}=$ pre-gestational stress + vehicle, $\mathrm{CF}=$ control + fluoxetine, $\mathrm{PGSF}=$ pre-gestational stress + fluoxetine. $(\mathrm{n}=5-8 / \mathrm{sex}$ ) group).

\begin{tabular}{lllll}
\hline & CV (6) & PGSV (5) & CF (8) & PGSF (5) \\
\hline $\begin{array}{c}\text { Postpartum weight } \\
\text { change (\%) }\end{array}$ & $11.6 \pm 3.3$ & $5.1 \pm 1.4$ & $6.6 \pm 1.4$ & $10.1 \pm 2.6$ \\
$\begin{array}{l}\text { Litter weight (g) } \\
\text { Litter size }\end{array}$ & $89.3 \pm 3.8$ & $98.5 \pm 2.5$ & $93.0 \pm 3.7$ & $97.3 \pm 5.4$ \\
& $12.8 \pm 0.7$ & $14.0 \pm 0.3$ & $13.4 \pm 0.8$ & $14.4 \pm 1.2$ \\
\hline
\end{tabular}

$\mathrm{t}=-2.40, \mathrm{df}=30, \mathrm{p}=0.02$ ). There were no significant differences in percent object novel recognition memory (novel exploration/novel + familiar exploration*100) at the $1 \mathrm{~h}$ and $24 \mathrm{~h}$ period or object location memory (novel place exploration/novel + familiar place exploration*100), or in distance travelled during these tests, between stressed and control females prior to breeding ( $p>0.1$, Table 1). There were no significant differences in the stressed females used for perinatal vehicle or fluoxetine treatment prior to administration of the drugs (p's $>0.2$ ). There was no effect of estrous phase on any measures.

\subsection{Breeding success}

Pre-gestationally stressed females, prior to SSRI administration (which began during gestation), were significantly less likely to maintain a pregnancy $\left(\chi^{2}(1,34)=4.08, p=0.04\right.$, Fig. $\left.2 \mathrm{D}\right)$, and were rebred significantly more times than controls $\left(\chi^{2}(1,34)=6.38\right.$, $\mathrm{p}=0.01$; Fig. 2E). During the postpartum period there was a significant condition by treatment interaction effect on percent weight gain $(F(1,20)=4.8, p=0.04)$ with PGSV dams tending to have less weight gain during lactation than control dams $(\mathrm{p}=0.06)$ (Table 2). There were no significant condition or treatment effects on the number of days pregnant, litter size, or litter weight.

\subsection{Maternal caregiving behaviors}

Overall there was a significant main effect of time spent in specific pup-directed behaviors during observations on the first week postpartum (repeated measures ANOVA main effect $\mathrm{F}(3,63)=15.0$, $\mathrm{p}=0.000001$ ) with dams spending more time blanket nursing and licking while on the nest than other behaviors. In line with previous work on maternal stress we found that in dams not administered fluoxetine, pre-gestational stress (PSGV) resulted in significantly more time nursing offspring when compared to non-stressed (CV) dams $\left(\mathrm{t}=2.52, \mathrm{df}=11, \mathrm{p}=0.03, \mathrm{\eta}_{\mathrm{p}}{ }^{2}=0.41 ;\right.$ Fig. $\left.3 \mathrm{~A}\right)$, regardless of maternal age in days at conception. $\mathrm{CF}$ dams nursed offspring significantly more than $\mathrm{CV}$ dams during the last portion of the first week of postpartum (PD3-6) $(\mathrm{p}=0.02$; Fig. 3B, significant interaction effect $\mathrm{F}(1$, $20)=5.7, p=0.03)$. Stressed dams, regardless of fluoxetine treatment, made significantly fewer bouts licking offspring $(F(1,20)=6.4$, $\mathrm{p}=0.02$, Fig. 3C/D).

\subsection{Corticosterone and $C B G$}

Perinatal fluoxetine treatment reversed the effect of pre-gestational stress on corticosterone levels in the mother (significant interaction effect $\mathrm{F}(1,17)=6.7, \mathrm{p}=0.02$, Fig. 4A) with PGSV females having significantly lower total serum corticosterone levels compared to all other groups (p's < 0.02). There was also a significant main effect of fluoxetine treatment on total corticosterone $(\mathrm{F}(1,17)=13.4$, $\mathrm{p}=0.002$, Fig. 4A), CBG levels $(\mathrm{F}(1,19)=6.5, \mathrm{p}=0.02$, Fig. $4 \mathrm{~B})$ and estimated free corticosterone levels $(\mathrm{F}(1,19)=12.1, \mathrm{p}=0.00248$, Fig. 4C), with perinatal fluoxetine treatment to dams, regardless of pregestational stress exposure having elevated levels of corticosterone and 

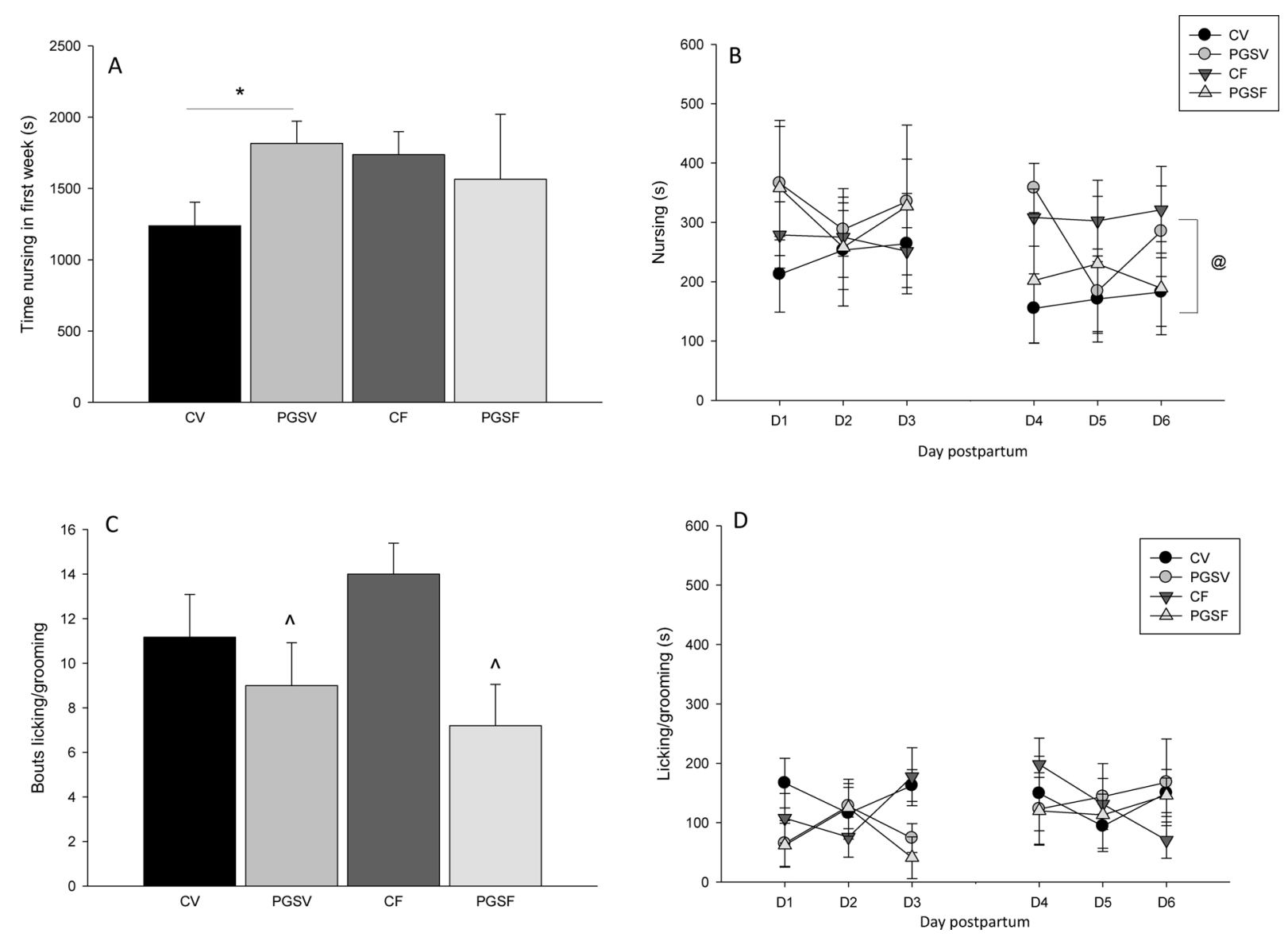

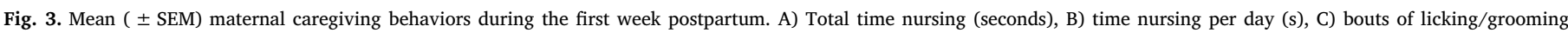

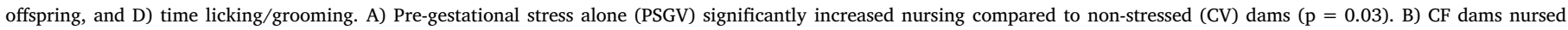

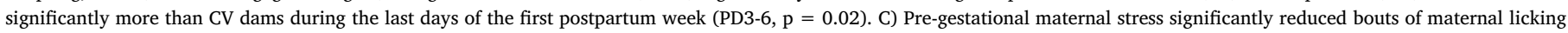

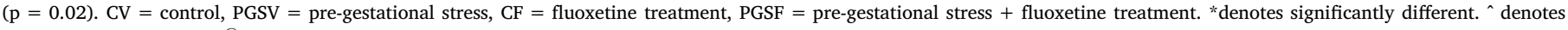
main effect of fluoxetine. ${ }^{@}$ denotes CF significantly different from CV from PD3-6. (n $=5-8 /$ group).

CBG and regardless of maternal age in days at conception or days past weaning. Maternal corticosterone levels significantly correlated with passive nursing ( $\mathrm{r}=-0.65, \mathrm{p}=0.001$, Fig. 4E) and marginally correlated with blanket nursing $(r=0.42, p=0.05$, Fig. 4D). There were no other significant effects of correlations between groups (p's $>0.1$ ).

\subsection{Immature neurons in the GCL}

For number of DCX-ir cells in the dorsal hippocampus (Fig. 5A) there was a significant main effect of fluoxetine treatment $(F(1,15)$ $=8.8, \mathrm{p}=0.01, \mathrm{n}_{\mathrm{p}}{ }^{2}=0.37$, Fig. $5 \mathrm{~B}, \mathrm{n}=9$ for fluoxetine, $\mathrm{n}=10$ for vehicle) with fluoxetine treated dams having a greater number of DCXir cells compared to controls dams, regardless of maternal age at conception or days past weaning. There were no other main effects or interaction effects or correlations between number of DCX-ir cells in the dorsal hippocampus and maternal corticosterone and CBG or maternal care (p's > 0.06).

\section{Discussion}

Although much research has focused on how maternal stress, maternal mental illnesses, and on how perinatal SSRI treatment affect offspring outcomes, there is little information on how these exposures influence maternal outcomes. The aim of our study was to investigate the long-term impact of pre-gestational stress on maternal outcomes and how SSRI treatment may modify these outcomes. Main findings show that 3 weeks of unpredictable stress increased anxiety-like behaviors in a novel environment, and significantly reduced the maintenance of pregnancy and breeding success in the dam. This pregestational stress also significantly altered maternal care-giving behavior by increasing time spent nursing and decreasing the number of bouts dams spent licking and grooming offspring. Perinatal SSRI treatment reversed the effects of pre-gestational stress on serum corticosterone, and increased CBG levels as well as hippocampal neurogenesis in the dam. This is the first work to show that perinatal SSRI treatment may be effective in ameliorating some of the lasting effects of pre-gestational stress on the dam.

\subsection{Pre-gestational stress effects on the dam}

Three weeks of chronic unpredictable stress significantly reduced weight gain, increased anxiety-like behavior in a novel environment, and decreased breeding success in adult females. This extends previous work showing that chronic unpredictable stress prior to pregnancy reduces sucrose consumption and activity in the open field test [4]. Similar chronic unpredictable stress paradigms have likewise demonstrated a reduction in weight gain and mobility in an open field environment in female rodents [61,62]. Taken together, such work demonstrates that chronic stress, especially prior to gestation, may mimic aspects of maternal affective disorders, such as anhedonia and anxiety.

We also found that this 3 week stress paradigm, prior to SSRI treatment, significantly reduced maintenance of pregnancy, despite evidence of sperm in vaginal smears. It is well accepted that exposure to acute or chronic stress markedly impact reproductive function via the reciprocal actions between the HPA and hypothalamic-pituitary- 

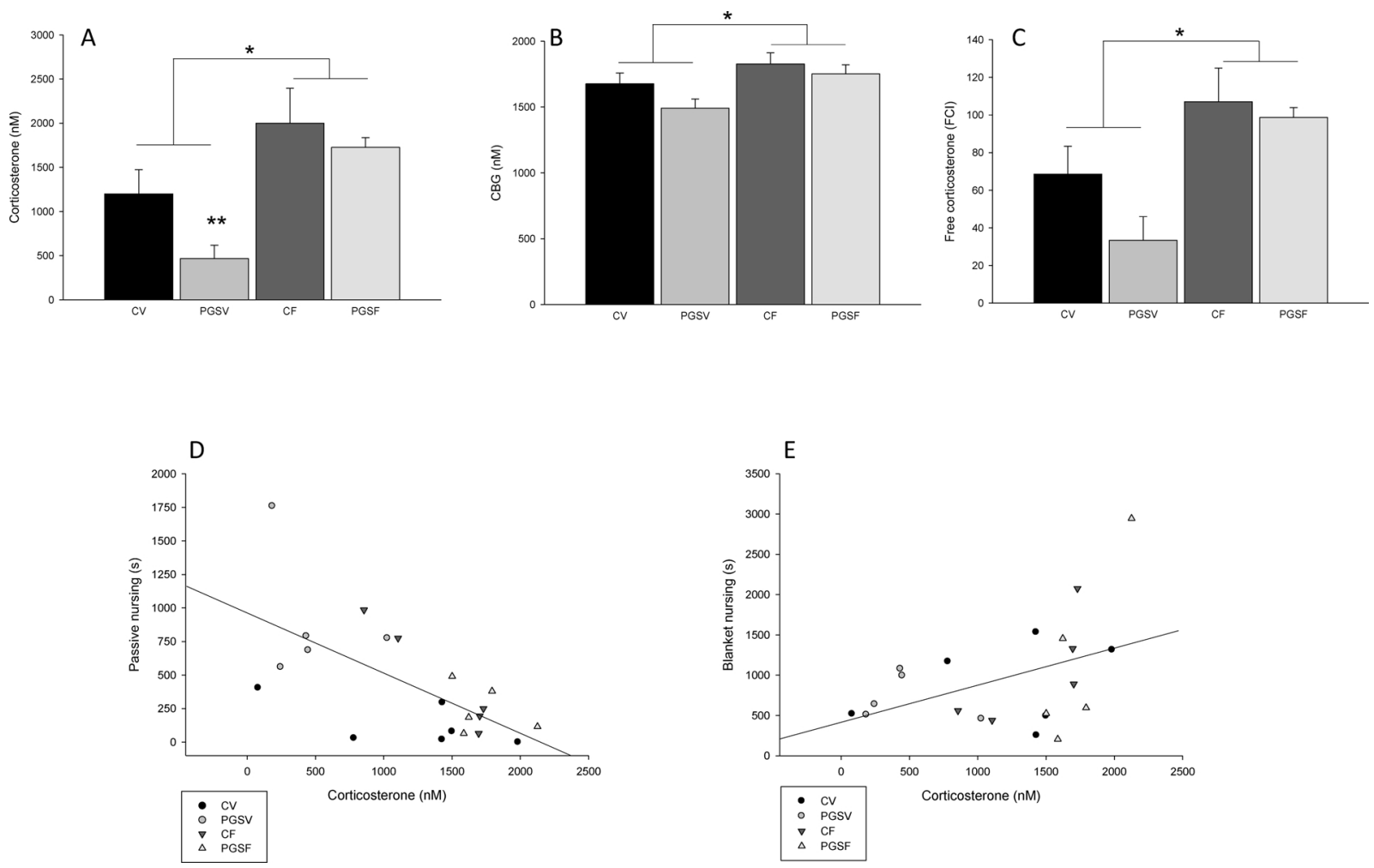

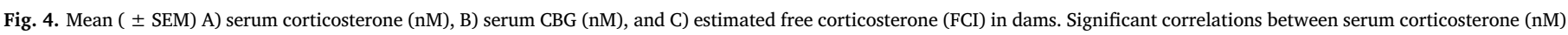

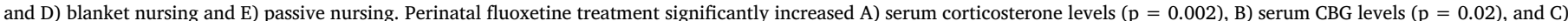

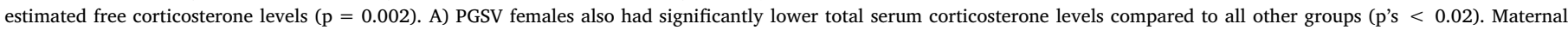

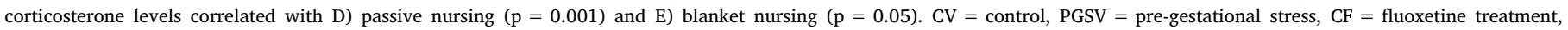
PGSF $=$ pre-gestational stress + fluoxetine treatment. ${ }^{* *}$ denotes significantly different from all other groups. ${ }^{*}$ denotes significantly different. ( $\mathrm{n}=5-7 /$ group).

gonadal (HPG) axis [63-65]. Most notably in females, mild acute stress or chronic stress will affect the HPG axis via central effects on gonadotropin secretion $[66,67]$, affecting onset of puberty and estrous cycle [68-70], but also sexual motivation and receptivity toward the male [71-75]. However, in the present experiment, all females, including those from the stressed group, were inseminated, as attested by the presence of sperm in the vaginal smears. This suggests that the higher percentage of reproductive failures observed in the stress group was not a result of a defect in estrous cycle or low proceptive/receptive behavior, although not quantified in the present work, but could be associated with embryo implantation or maintenance of gestation [76].

\subsection{Long-term effects of pre-gestational stress and perinatal SSRIs on maternal caregiving behaviors}

We found that pre-gestational chronic stress has an enduring effect on maternal caregiving by increasing nursing and decreasing licking and grooming of pups. This extends previous research which reports
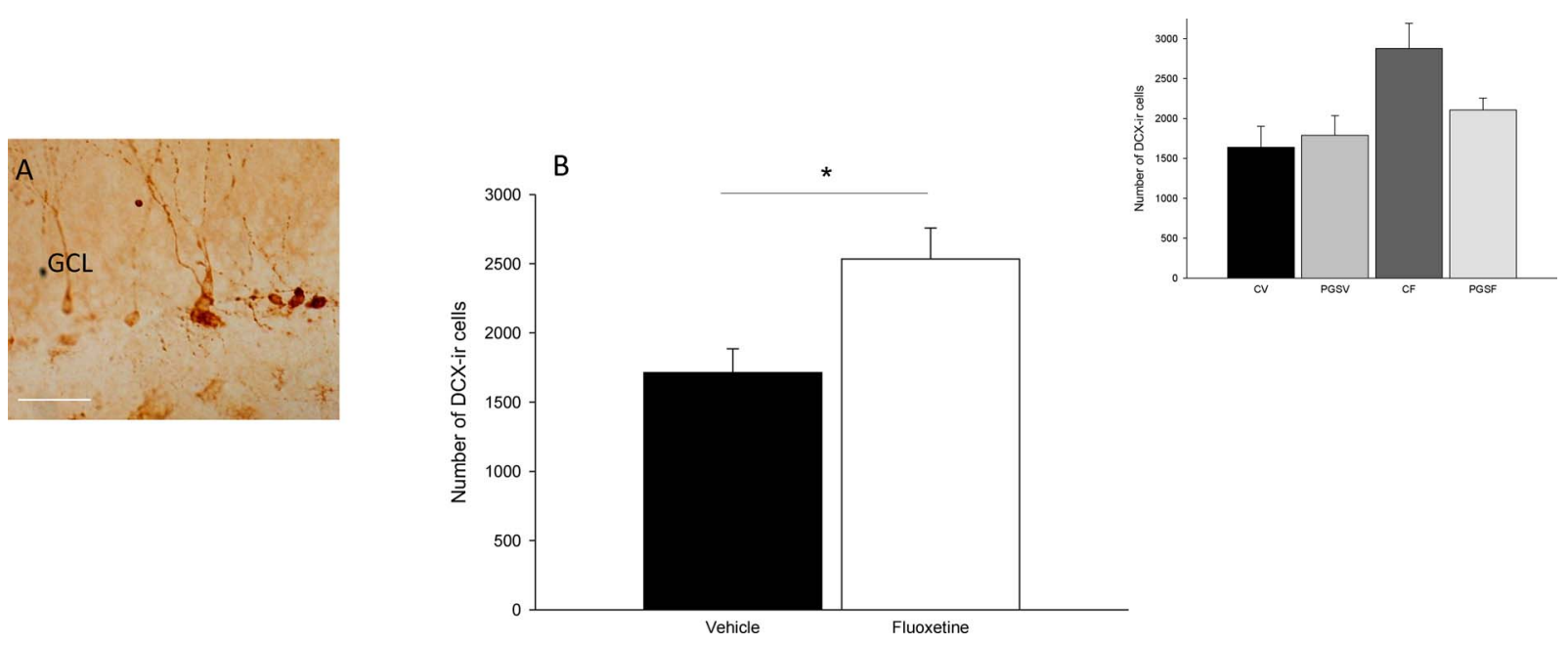

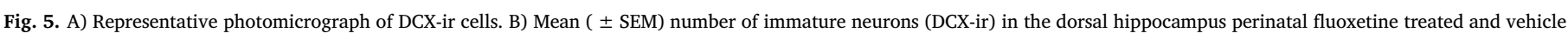

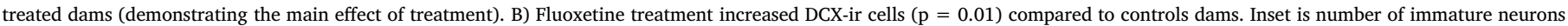

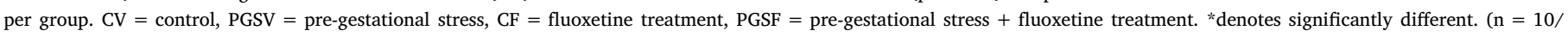
vehicle, $\mathrm{n}=9$ /fluoxetine). 
that stress during gestation can increase maternal nursing, decrease licking, and alter maternal caregiving behaviors [8-12]. We add to this body of knowledge by showing that stress prior to gestation also effects maternal caregiving, weeks after the stress is discontinued.

Although we did not find perinatal fluoxetine treatment reversed the effects of pre-gestational maternal stress on maternal care-giving behaviors, we did find that non-stressed perinatal-fluoxetine treated dams spent more time nursing offspring that untreated controls. This is in line with our previous work showing that perinatal fluoxetine treatment increases arched-back nursing of pups in the first week postpartum [77] and recent research showing that perinatal venlafaxine treatment (a serotonin-norepinephrine reuptake inhibitor) increases nursing in the dam [78]. The effects of SSRIs on maternal nursing behaviors may not be surprising as previous research has shown a role for 5-HT and the 5-HT system in various aspects of maternal caregiving behaviors [2]. For example, tryptophan hydroxylase-2 knockout mice show lower levels of arched-back nursing postures compared to controls $[80,81]$. Other recent work has shown that the 5$\mathrm{HT}_{2 \mathrm{~A}}$ and $5-\mathrm{HT}_{2 \mathrm{C}}$ receptors are likely key mediators for serotonin's role in nursing as antagonism of the $5 \mathrm{HT}_{2 \mathrm{~A}}$ receptor increases crouching behavior duration [82] and antagonism of the $5-\mathrm{HT}_{2 \mathrm{C}}$ receptor decreases nursing [83]. Such work suggests that changes in serotonergic system functioning, as a result of 5-HT receptor antagonism or perinatal SSRI exposure, modify maternal caregiving. This is confirmed by recent research showing that the dorsal raphe, which provides the majority of serotonergic input to the brain, is a key mediator in both anti- and proparental behavior $[84,85]$. However, the exact mechanisms elucidating how SSRIs may act on the 5-HT system to alter maternal nursing behaviors remains to be determined.

\subsection{Perinatal SSRIs, pre-gestational stress, and the maternal corticosterone and $C B G$}

Our findings show that pre-gestational maternal stress has a longterm impact on circulating corticosterone levels with reductions in corticosterone levels into the late postpartum, weeks after the stress was experienced. This shows that prior stress exposure can dampen circulating corticosterone levels, particularly in response to additional stressors $[17,77,86]$. Interestingly, perinatal fluoxetine treatment prevented this effect of pre-gestational stress on corticosterone levels by increasing serum corticosterone and CBG levels in the mother. We have previously shown that while maternal stress during pregnancy lowers morning serum corticosterone levels compared to controls at weaning [77], postnatal fluoxetine treatment to the dam does not reverse these gestational stress effects but, significantly reduces CBG levels in the dam. This contrasts with our new findings that perinatal SSRI treatment increases serum CBG, which probably accounts for the increases in both total and free corticosterone levels that occur irrespective of prenatal stress in the SSRI treated dams. However, this effect of SSRI treatment has a major effect on abrogating the perinatal stress-induced reduction in total and free serum corticosterone levels in prenatally stressed dams. These findings indicate a critical period, in which the timing of both the maternal stress and maternal fluoxetine treatment may differentially impact the maternal corticosterone and CBG. These findings may also be due to the administration method (orally in the present study versus osmotic mini-pump) or the rodent supplier (Harlan Laboratories, USA versus Charles River Laboratories, France). Indeed Sprague-Dawley rats from different colonies have different HPA axis responses in terms of circulating corticosterone levels and CBG $[87,88]$. Regardless, perinatal SSRI treatment increases both corticosterone and CBG in the dam, and may be beneficial when considering individuals with a history of stress and depression prior to pregnancy.

We also found that maternal levels of free corticosterone were correlated with specific nursing behaviors in the dam. Glucocorticoids have long been tied to maternal caregiving in humans and rodents [89-92] and due to the role of corticosterone in milk production and let down, it is perhaps not surprising that this relationship exists [55]. Although causality cannot be established, nursing stimulation may, in fact, decrease corticosterone levels, especially when blanket nursing occurs, due to the ventral stimulation and 'stress'-decreasing effects of touch $[1,93]$. Findings from the present study add to a growing body of literature which suggest that infant touch, with or without lactation, can affect the physiology of the mother.

\subsection{Pre-gestational stress, perinatal SSRIs, and hippocampal neurogenesis in the maternal brain}

Relationships between hippocampal neurogenesis, stress, behavioral phenotype of depression, and efficacy of antidepressant medication treatment have been reported [94-97]. However, much of this research has focused on males and, to a lesser extent, virgin females. In the present study we found that perinatal fluoxetine treatment significantly increased the number of immature neurons in the dorsal hippocampus of the mother. This effect was more pronounced in dams that had not been stressed prior to gestation. We, and others, have previously reported that fluoxetine treatment to the dam during the postpartum period also increases the number of immature neurons in the maternal hippocampus weeks after giving birth [77], but not at the time of weaning $[40,42]$. Recent work also shows that venlafaxine, a serotonin norepinephrine reuptake inhibitor (SNRI), can also increase the number of immature neurons in the maternal brain [78]. This work points to a role for perinatal SSRIs in increasing hippocampal neurogenesis in the mother, which may contribute to the therapeutic effects of SSRIs in treating maternal affective disorders.

It is important to note that we did not find an enduring effect of pregestational stress on the number of immature neurons in the dorsal hippocampus of the mother. This is consistent with our previous work showing no long-term effect of stress during pregnancy on hippocampal neurogenesis in the maternal brain [42]. It may be that pre-gestational stress affects neurogenesis in the ventral portion of the hippocampus, or other measures of plasticity in the hippocampus and areas of the maternal brain $[11,40]$. We have shown that gestational stress can increase presynaptic density in the maternal prefrontal cingulate gyrus region [42] and these effects may be evident in other brain areas important for maternal care. Together, this suggests that while pre-gestational and gestational stress may not have a long-term effect on neurogenesis in the maternal hippocampus, there may be enduring effects of maternal stress on additional brain regions.

\section{Conclusions}

Maternal pre-conceptual mental health plays a critical role in regulating neurobehavioral outcomes, as suggested in recent clinical research $[98,99]$. The current work shows that chronic unpredictable stress prior to gestation induces aspects of maternal affective disorders. These pre-gestational stress effects are evident at conception as well as in maternal caregiving behaviors. Interestingly perinatal treatment with fluoxetine, a popular SSRI used during the perinatal period, did not prevent the effects of pre-gestational stress on maternal caregiving behaviors, but did prevent the effect of pre-gestational stress on serum corticosterone levels and increased serum CBG levels and hippocampal neurogenesis in the maternal brain. Our results support the importance of maternal health prior to gestation, and add to a growing body of literature focused on understanding how perinatal SSRI treatment may improve the health and well-being of mothers. 


\section{Funding}

JLP is funded by a Brain \& Behavior Research Foundation NARSAD Young Investigator Grant. TDC is funded by the Region Bretagne, Rennes Metropoles and INSERM. MG received the 2015-2016 Student Enhancement Award from the CRSCA at Ohio University to aid in this work.

\section{Acknowledgement}

We thank Clare Vesel for her work on this project.

\section{References}

[1] J.L. Pawluski, J.S. Lonstein, A.S. Fleming, The neurobiology of postpartum anxiety and depression, Trends Neurosci. 40 (2) (2017) 106-120.

[2] M. Gemmel, E. Bögi, C. Ragan, M. Hazlett, M. Dubovicky, D.L. Van den Hove, T.F. Oberlander, T.D. Charlier, J.L. Pawluski, Perinatal selective serotonin reuptake inhibitor medication (SSRI) effects on social behaviors, neurodevelopment and the epigenome, Neurosci. Biobehav. Rev. (2017) Epub ahead of print.

[3] M. Glover, S. Clinton, Of rodents and humans: a comparative review of the neurobehavioral effects of early life SSRI exposure in preclinical and clinical research, Int. J. Dev. Neurosci. 51 (2016) 50-72.

[4] Y. Huang, H. Xu, H. Li, H. Yang, Y. Chen, X. Shi, Pre-gestational stress reduces the ratio of 5-HIAA to 5-HT and the expression of 5-HT1A receptor and serotonin transporter in the brain of foetal rat, BMC Neurosci. 13 (2012) 22.

[5] T. Field, Psychologically depressed parents, in: M. Bornstein (Ed.), Handbook of Parenting, L. Erlbaum Associates, New Jersey, 1995.

[6] T. Field, B. Healy, M. Goldstein, M. Guthertz, Behavior-state matching and synchrony in mother-infant interactions of nondepressed versus depressed dyads, Dev. Psychobiol. 26 (1) (1990) 7-14.

[7] A.S. Fleming, D.N. Ruble, G.L. Flett, D. Shaul, Postpartum adjustment in first-time mothers: relations between mood, maternal attitudes and mother-infant interactions', Dev. Psychobiol. 24 (1988) 71-81.

[8] S. Brummelte, J.L. Pawluski, L.A. Galea, High post-partum levels of corticosterone given to dams influence postnatal hippocampal cell proliferation and behavior of offspring: a model of post-partum stress and possible depression, Horm. Behav. 50 (3) (2006) 370-382

[9] L. Belnoue, S. Malvaut, E. Ladeveze, D.N. Abrous, M. Koehl, Plasticity in the olfactory bulb of the maternal mouse is prevented by gestational stress, Sci. Rep. 6 (2016) 37615.

[10] F.A. Champagne, M.J. Meaney, Stress during gestation alters postpartum maternal care and the development of the offspring in a rodent model, Biol. Psychiatry 59 (12) (2006) 1227-1235.

[11] A. Haim, M. Sherer, B. Leuner, Gestational stress induces persistent depressive-like behavior and structural modifications within the postpartum nucleus accumbens, Eur. J. Neurosci. 40 (12) (2014) 3766-3773.

[12] K.M. Hillerer, I.D. Neumann, D.A. Slattery, From stress to postpartum mood and anxiety disorders: how chronic peripartum stress can impair maternal adaptations, Neuroendocrinology 95 (1) (2012) 22-38.

[13] E.L. Moses-Kolko, M.S. Horner, M.L. Phillips, A.E. Hipwell, J.E. Swain, In search of neural endophenotypes of postpartum psychopathology and disrupted maternal caregiving, J. Neuroendocrinol. 26 (10) (2014) 665-684.

[14] J.L. Pawluski, E. Csaszar, E. Savage, M. Martinez-Claros, H.W. Steinbusch, D. van den Hove, Effects of stress early in gestation on hippocampal neurogenesis and glucocorticoid receptor density in pregnant rats, Neuroscience 290 (2015) 379-388.

[15] J.L. Pawluski, D.L. van den Hove, I. Rayen, J. Prickaerts, H.W. Steinbusch, Stress and the pregnant female: impact on hippocampal cell proliferation, but not affec tive-like behaviors, Horm. Behav. 59 (4) (2011) 572-580.

[16] N. Maghsoudi, R. Ghasemi, Z. Ghaempanah, A.M. Ardekani, E. Nooshinfar, A. Tahzibi, Effect of chronic restraint stress on HPA axis activity and expression of BDNF and Trkb in the hippocampus of pregnant rats: possible contribution in depression during pregnancy and postpartum period, Basic Clin. Neurosci. 5 (2) (2014) 131-137.

[17] J.L. Pawluski, A. Valenca, A.I. Santos, J.P. Costa-Nunes, H.W. Steinbusch, T. Strekalova, Pregnancy or stress decrease complexity of CA3 pyramidal neurons in the hippocampus of adult female rats, Neuroscience 227 (2012) 201-210.

[18] K.M. Hillerer, I.D. Neumann, S. Couillard-Despres, L. Aigner, D.A. Slattery, Lactation-induced reduction in hippocampal neurogenesis is reversed by repeated stress exposure, Hippocampus 24 (6) (2014) 673-683.

[19] S. Brummelte, L.A. Galea, Chronic corticosterone during pregnancy and postpartum affects maternal care, cell proliferation and depressive-like behavior in the dam, Horm. Behav. 58 (8) (2010) 769-779.

[20] J.L. Workman, S. Brummelte, L.A. Galea, Postpartum corticosterone administration reduces dendritic complexity and increases the density of mushroom spines of hippocampal CA3 arbours in dams, J. Neuroendocrinol. 25 (2) (2013) 119-130.

[21] V. Lemaire, J.M. Billard, P. Dutar, O. George, P.V. Piazza, J. Epelbaum, M. Le Moal, W. Mayo, Motherhood-induced memory improvement persists across lifespan in rats but is abolished by a gestational stress, Eur. J. Neurosci. 23 (12) (2006) 3368-3374.

[22] A. Dranovsky, R. Hen, Hippocampal neurogenesis: regulation by stress and antidepressants, Biol. Psychiatry 59 (12) (2006) 1136-1143.

[23] A.J. Eisch, H.A. Cameron, J.M. Encinas, L.A. Meltzer, G.L. Ming, L.S. OverstreetWadiche, Adult neurogenesis, mental health, and mental illness: hope or hype? J. Neurosci. 28 (46) (2008) 11785-11791.

[24] A.J. Eisch, D. Petrik, Depression and hippocampal neurogenesis: a road to remission? Science 338 (6103) (2012) 72-75.

[25] J.L. Pawluski, L.A. Galea, Reproductive experience alters hippocampal neurogenesis during the postpartum period in the dam, Neuroscience 149 (1) (2007) 53-67.

[26] B. Leuner, E.R. Glasper, E. Gould, Parenting and plasticity, Trends Neurosci. 33 (10) (2010) 465-473.

[27] J.L. Pawluski, L.A. Galea, Hippocampal morphology is differentially affected by reproductive experience in the mother, J. Neurobiol. 66 (1) (2006) 71-81.

[28] B. Leuner, S. Sabihi, The birth of new neurons in the maternal brain: hormonal regulation and functional implications, Front. Neuroendocrinol. 41 (2016) 99-113.

[29] R.A. Charlton, S. Jordan, A. Pierini, E. Garne, A.J. Neville, A.V. Hansen, R. Gini, D. Thayer, K. Tingay, A. Puccini, H.J. Bos, A.M. Nybo Andersen, M. Sinclair, H. Dolk, L.T. de Jong-van den Berg, Selective serotonin reuptake inhibitor prescribing before, during and after pregnancy: a population-based study in six European regions, BJOG 122 (7) (2015) 1010-1020.

[30] W.O. Cooper, M.E. Willy, S.J. Pont, W.A. Ray, Increasing use of antidepressants in pregnancy, Am. J. Obstet. Gynecol. 196 (6) (2007) 544 e1-5.

[31] T.F. Oberlander, W. Warburton, S. Misri, J. Aghajanian, C. Hertzman, Neonatal outcomes after prenatal exposure to selective serotonin reuptake inhibitor antidepressants and maternal depression using population-based linked health data, Arch. Gen. Psychiatry 63 (8) (2006) 898-906.

[32] H. Zoega, H. Kieler, M. Norgaard, K. Furu, U. Valdimarsdottir, L. Brandt, B. Haglund, Use of SSRI and SNRI antidepressants during pregnancy: a populationbased study from Denmark, Iceland, Norway and Sweden, PLoS One 10 (12) (2015) e0144474.

[33] N. Barden, J.M. Reul, F. Holsboer, Do antidepressants stabilize mood through actions on the hypothalamic-pituitary-adrenocortical system? Trends Neurosci. 18 (1) (1995) 6-11

[34] L. Santarelli, M. Saxe, C. Gross, A. Surget, F. Battaglia, S. Dulawa, N. Weisstaub, J. Lee, R. Duman, O. Arancio, C. Belzung, R. Hen, Requirement of hippocampal neurogenesis for the behavioral effects of antidepressants, Science 301 (5634) (2003) 805-809.

[35] J.E. Malberg, R.S. Duman, Cell proliferation in adult hippocampus is decreased by inescapable stress: reversal by fluoxetine treatment, Neuropsychopharmacology 28 (9) (2003) 1562-1571.

[36] W.M. Weikum, L.C. Mayes, R.E. Grunau, U. Brain, T.F. Oberlander, The impact of prenatal serotonin reuptake inhibitor (SRI) antidepressant exposure and maternal mood on mother-infant interactions at 3 months of age, Infant Behav. Dev. 36 (4) (2013) 485-493.

[37] M.C. Logsdon, K. Wisner, B.H. Hanusa, Does maternal role functioning improve with antidepressant treatment in women with postpartum depression? J. Womens Health (Larchmt) 18 (1) (2009) 85-90.

[38] J. McFarland, A.L. Salisbury, C.L. Battle, K. Hawes, K. Halloran, B.M. Lester, Major depressive disorder during pregnancy and emotional attachment to the fetus, Arch. Womens Ment. Health 14 (5) (2011) 425-434.

[39] J.M. Johns, P.W. Joyner, M.S. McMurray, D.L. Elliott, V.E. Hofler, C.L. Middleton, K. Knupp, K.W. Greenhill, L.M. Lomas, C.H. Walker, The effects of dopaminergic/ serotonergic reuptake inhibition on maternal behavior, maternal aggression, and oxytocin in the rat, Pharmacol. Biochem. Behav. 81 (4) (2005) 769-785.

[40] J.L. Workman, A.R. Gobinath, N.F. Kitay, C. Chow, S. Brummelte, L.A. Galea, Parity modifies the effects of fluoxetine and corticosterone on behavior, stress reactivity, and hippocampal neurogenesis, Neuropharmacology 105 (2016) 443-453.

[41] J. Pawluski, T. Charlier, M. Fillet, V. Houbart, H. Crispin, H. Steinbusch, D. van den Hove, Chronic fluoxetine treatment and maternal adversity differentially alter neurobehavioral outcomes in the rat dam, Behav. Brain Res. 228 (1) (2012) $159-168$.

[42] M. Gemmel, I. Rayen, E. van Donkelaar, T. Loftus, H.W. Steinbusch, N. Kokras, C. Dalla, J.L. Pawluski, Gestational stress and fluoxetine treatment differentially affect plasticity, methylation and serotonin levels in the PFC and hippocampus of rat dams, Neuroscience 327 (2016) 32-43.

[43] Y. Huang, X. Shi, H. Xu, H. Yang, T. Chen, S. Chen, X. Chen, Chronic unpredictable stress before pregnancy reduce the expression of brain-derived neurotrophic facto and N-methyl-D-aspartate receptor in hippocampus of offspring rats associated with impairment of memory, Neurochem. Res. 35 (7) (2010) 1038-1049.

[44] A.L. Martin, R.E. Brown, The lonely mouse: verification of a separation-induced model of depression in female mice, Behav. Brain Res. 207 (1) (2010) 196-207.

[45] B.S. McEwen, Glucocorticoids, depression, and mood disorders: structural remodeling in the brain, Metabolism 54 (5 Suppl. 1) (2005) 20-23.

[46] A. Ennaceur, J. Delacour, A new one-trial test for neurobiological studies of memory in rats. 1: Behavioral data, Behav. Brain Res. 31 (1) (1988) 47-59.

[47] A.H. Macbeth, C. Gautreaux, V.N. Luine, Pregnant rats show enhanced spatial memory, decreased anxiety, and altered levels of monoaminergic neurotransmitters, Brain Res. 1241 (2008) 136-147.

[48] L. Prut, C. Belzung, The open field as a paradigm to measure the effects of drugs on anxiety-like behaviors: a review, Eur. J. Pharmacol. 463 (1-3) (2003) 3-33.

[49] M. Gemmel, M. Hazlett, E. Bogi, S. De Lacalle, L.A. Hill, N. Kokras, G.L. Hammond, C. Dalla, T.D. Charlier, J.L. Pawluski, Perinatal fluoxetine effects on social play, the HPA system, and hippocampal plasticity in pre-adolescent male and female rats: interactions with pre-gestational maternal stress, Psychoneuroendocrinology 84 (2017) 159-171.

[50] J.L. Pawluski, E. van Donkelaar, Z. Abrams, V. Houbart, M. Fillet, H.W. Steinbusch, T.D. Charlier, Fluoxetine dose and administration method differentially affect 
hippocampal plasticity in adult female rats, Neural Plast. 2014 (2014) 123026.

[51] L. Knaepen, I. Rayen, T.D. Charlier, M. Fillet, V. Houbart, M. van Kleef, H.W. Steinbusch, J. Patijn, D. Tibboel, E.A. Joosten, J.L. Pawluski, Developmental fluoxetine exposure normalizes the long-term effects of maternal stress on postoperative pain in Sprague-Dawley rat offspring, PLoS One 8 (2) (2013) e57608.

[52] A. Corbett, A. McGowin, S. Sieber, T. Flannery, B. Sibbitt, A method for reliable voluntary oral administration of a fixed dosage $(\mathrm{mg} / \mathrm{kg}$ ) of chronic daily medication to rats, Lab. Anim. 46 (4) (2012) 318-324.

[53] J.L. Pawluski, I. Rayen, N.A. Niessen, S. Kristensen, E.L. van Donkelaar, J. Balthazart, H.W. Steinbusch, T.D. Charlier, Developmental fluoxetine exposure differentially alters central and peripheral measures of the HPA system in adolescent male and female offspring, Neuroscience 220 (2012) 131-141.

[54] V. Houbart, A.C. Servais, T.D. Charlier, J.L. Pawluski, F. Abts, M. Fillet, A validated microfluidics-based LC-chip-MS/MS method for the quantitation of fluoxetine and norfluoxetine in rat serum, Electrophoresis 33 (22) (2012) 3370-3379.

[55] J.L. Pawluski, T.D. Charlier, S.E. Lieblich, G.L. Hammond, L.A. Galea, Reproductive experience alters corticosterone and CBG levels in the rat dam, Physiol. Behav. 96 (1) (2009) 108-114.

[56] G.L. Hammond, P.L. Lahteenmaki, A versatile method for the determination of serum cortisol binding globulin and sex hormone binding globulin binding capacities, Clin. Chim. Acta 132 (1) (1983) 101-110.

[57] J.L. Pawluski, I. Rayen, N.A. Niessen, S. Kristensen, E.L.v. Donkelaar, J. Balthazart, H.W. Steinbusch, T.D. Charlier, Developmental fluoxetine exposure differentially alters central and peripheral measures of the HPA system in adolescent male and female offspring, Neuroscience 220 (2012) 131-141.

[58] I. Rayen, M. Gemmel, G. Pauley, H.W. Steinbusch, J.L. Pawluski, Developmental exposure to SSRIs, in addition to maternal stress, has long-term sex-dependent effects on hippocampal plasticity, Psychopharmacology (Berl) 232 (7) (2015) 1231-1244.

[59] I. Rayen, D.L. van den Hove, J. Prickaerts, H.W. Steinbusch, J.L. Pawluski, Fluoxetine during development reverses the effects of prenatal stress on depressivelike behavior and hippocampal neurogenesis in adolescence, PLoS One 6 (9) (2011) e24003.

[60] K.M. Hillerer, S.O. Reber, I.D. Neumann, D.A. Slattery, Exposure to chronic pregnancy stress reverses peripartum-associated adaptations: implications for postpartum anxiety and mood disorders, Endocrinology 152 (10) (2011) 3930-3940.

[61] C. Dalla, K. Antoniou, N. Kokras, G. Drossopoulou, G. Papathanasiou, S. Bekris, S. Daskas, Z. Papadopoulou-Daifoti, Sex differences in the effects of two stress paradigms on dopaminergic neurotransmission, Physiol. Behav. 93 (3) (2008) 595-605.

[62] C. Dalla, K. Antoniou, G. Drossopoulou, M. Xagoraris, N. Kokras, A. Sfikakis, Z. Papadopoulou-Daifoti, Chronic mild stress impact: are females more vulnerable? Neuroscience 135 (3) (2005) 703-714.

[63] A.C. Geraghty, D. Kaufer, Glucocorticoid regulation of reproduction, Adv. Exp. Med. Biol. 872 (2015) 253-278.

[64] C. Rivier, S. Rivest, Effect of stress on the activity of the hypothalamic-pituitarygonadal axis: peripheral and central mechanisms, Biol. Reprod. 45 (4) (1991) 523-532.

[65] D. Toufexis, M.A. Rivarola, H. Lara, V. Viau, Stress and the reproductive axis, J. Neuroendocrinol. 26 (9) (2014) 573-586.

[66] H. Dobson, S. Ghuman, S. Prabhakar, R. Smith, A conceptual model of the influence of stress on female reproduction, Reproduction 125 (2) (2003) 151-163.

[67] E. Keen-Rhinehart, V. Michopoulos, D.J. Toufexis, E.I. Martin, H. Nair, K.J. Ressler, M. Davis, M.J. Owens, C.B. Nemeroff, M.E. Wilson, Continuous expression of corticotropin-releasing factor in the central nucleus of the amygdala emulates the dysregulation of the stress and reproductive axes, Mol. Psychiatry 14 (1) (2009) $37-50$.

[68] S.L. Baker, A.C. Kentner, A.T. Konkle, L. Santa-Maria Barbagallo, C. Bielajew, Behavioral and physiological effects of chronic mild stress in female rats, Physiol. Behav. 87 (2) (2006) 314-322.

[69] A.S. Gonzalez, E.L. Rodriguez Echandia, R. Cabrera, M.R. Foscolo, Neonatal chronic stress induces subsensitivity to chronic stress in adult rats: II. Effects on estrous cycle in females, Physiol. Behav. 56 (3) (1994) 591-595.

[70] X.F. Li, M.H. Hu, S.Y. Li, C. Geach, A. Hikima, S. Rose, M.P. Greenwood, M. Greenwood, D. Murphy, L. Poston, S.L. Lightman, K.T. O'Byrne, Overexpression of corticotropin releasing factor in the central nucleus of the amygdala advances puberty and disrupts reproductive cycles in female rats, Endocrinology 155 (10) (2014) 3934-3944.

[71] C.A. Frye, Z.A. Orecki, Prenatal stress alters reproductive responses of rats in behavioral estrus and paced mating of hormone-primed rats, Horm. Behav. 42 (4) (2002) 472-483.

[72] A.S. Gonzalez Jatuff, M. Berastegui, C.I. Rodriguez, E.L. Rodriguez Echandia, Permanent and transient effects of repeated preweaning stress on social and sexual behaviors of rats, Stress 3 (2) (1999) 97-106.

[73] S.C. Heinrichs, H. Min, S. Tamraz, M. Carmouche, S.A. Boehme, W.W. Vale, Antisexual and anxiogenic behavioral consequences of corticotropin-releasing factor overexpression are centrally mediated, Psychoneuroendocrinology 22 (4) (1997) $215-224$.
[74] L. Uphouse, A. Selvamani, C. Lincoln, L. Morales, D. Comeaux, Mild restraint reduces the time hormonally primed rats spend with sexually active males, Behav. Brain Res. 157 (2) (2005) 343-350.

[75] H. Yoon, W.S. Chung, Y.Y. Park, I.H. Cho, Effects of stress on female rat sexual function, Int. J. Impot. Res. 17 (1) (2005) 33-38.

[76] D. deCatanzaro, E. Macniven, Psychogenic pregnancy disruptions in mammals, Neurosci. Biobehav. Rev. 16 (1) (1992) 43-53.

[77] J.L. Pawluski, T.D. Charlier, M. Fillet, V. Houbart, H.T. Crispin, H.W. Steinbusch, D.L. van den Hove, Chronic fluoxetine treatment and maternal adversity differentially alter neurobehavioral outcomes in the rat dam, Behav. Brain Res. 228 (1) (2012) 159-168.

[78] K. Belovicova, E. Bogi, R. Koprdova, E. Ujhazy, M. Mach, M. Dubovicky, Effects of venlafaxine and chronic unpredictable stress on behavior and hippocampal neurogenesis of rat dams, Neuro Endocrinol. Lett. 38 (1) (2017) 19-26.

[80] N. Alenina, D. Kikic, M. Todiras, V. Mosienko, F. Qadri, R. Plehm, P. Boye, L. Vilianovitch, R. Sohr, K. Tenner, H. Hortnagl, M. Bader, Growth retardation and altered autonomic control in mice lacking brain serotonin, Proc. Natl. Acad. Sci. U. S. A. 106 (25) (2009) 10332-10337.

[81] M. Angoa-Perez, M.J. Kane, C.E. Sykes, S.A. Perrine, M.W. Church, D.M. Kuhn, Brain serotonin determines maternal behavior and offspring survival, Genes Brain Behav. 13 (7) (2014) 579-591.

[82] S.E. Keer, J.M. Stern, Dopamine receptor blockade in the nucleus accumbens inhibits maternal retrieval and licking, but enhances nursing behavior in lactating rats, Physiol. Behav. 67 (5) (1999) 659-669.

[83] C. Zhao, M. Li, c-Fos identification of neuroanatomical sites associated with haloperidol and clozapine disruption of maternal behavior in the rat, Neuroscience 166 (4) (2010) 1043-1055.

[84] J. Kohl, A.E. Autry, C. Dulac, The neurobiology of parenting: a neural circuit perspective, Bioessays 39 (1) (2017) 1-11.

[85] M.A. Holschbach, J.S. Lonstein, Motherhood and infant contact regulate neuroplasticity in the serotonergic midbrain dorsal raphe, Psychoneuroendocrinology 76 (2017) 97-106.

[86] M. Darnaudery, I. Dutriez, O. Viltart, S. Morley-Fletcher, S. Maccari, Stress during gestation induces lasting effects on emotional reactivity of the dam rat, Behav. Brain Res. 153 (1) (2004) 211-216.

[87] T.S. Bodnar, L.A. Hill, M.D. Taves, W. Yu, K.K. Soma, G.L. Hammond, J. Weinberg, Colony-specific differences in endocrine and immune responses to an inflammatory challenge in female Sprague Dawley rats, Endocrinology 156 (12) (2015) 4604-4617.

[88] L.A. Hill, T.S. Bodnar, J. Weinberg, G.L. Hammond, Corticosteroid-binding globulin is a biomarker of inflammation onset and severity in female rats, J. Endocrinol. 230 (2) (2016) 215-225.

[89] A.S. Fleming, M. Steiner, C. Corter, Cortisol, hedonics, and maternal responsiveness in human mothers, Horm. Behav. 32 (1997) 85-98.

[90] M.D. Graham, S.L. Rees, M. Steiner, A.S. Fleming, The effects of adrenalectomy and corticosterone replacement on maternal memory in postpartum rats, Horm. Behav. 49 (3) (2006) 353-361.

[91] S.L. Rees, S. Panesar, M. Steiner, A.S. Fleming, The effects of adrenalectomy and corticosterone replacement on induction of maternal behavior in the virgin female rat, Horm. Behav. 49 (3) (2006) 337-345.

[92] S.L. Rees, S. Panesar, M. Steiner, A.S. Fleming, The effects of adrenalectomy and corticosterone replacement on maternal behavior in the postpartum rat, Horm. Behav. 46 (4) (2004) 411-419.

[93] C.M. Ragan, J.S. Lonstein, Differential postpartum sensitivity to the anxiety-modulating effects of offspring contact is associated with innate anxiety and brainstem levels of dopamine beta-hydroxylase in female laboratory rats, Neuroscience 256 (2014) 433-444.

[94] J.L. Pawluski, S. Brummelte, C.K. Barha, T.M. Crozier, L.A. Galea, Effects of steroid hormones on neurogenesis in the hippocampus of the adult female rodent during the estrous cycle, pregnancy, lactation and aging, Front. Neuroendocrinol. 30 (3) (2009) 343-357.

[95] J.E. Malberg, A.J. Eisch, E.J. Nestler, R.S. Duman, Chronic antidepressant treatment increases neurogenesis in adult rat hippocampus, J. Neurosci. 20 (24) (2000) 9104-9110.

[96] O.F. O'Leary, J.F. Cryan, A ventral view on antidepressant action: roles for adult hippocampal neurogenesis along the dorsoventral axis, Trends Pharmacol. Sci. 35 (12) (2014) 675-687.

[97] A. Tanti, C. Belzung, Neurogenesis along the septo-temporal axis of the hippocampus: are depression and the action of antidepressants region-specific? Neuroscience 252 (2013) 234-252.

[98] H.K. Brown, J.G. Ray, A.S. Wilton, Y. Lunsky, T. Gomes, S.N. Vigod, Association between serotonergic antidepressant use during pregnancy and autism spectrum disorder in children, JAMA 317 (15) (2017) 1544-1552.

[99] A. Mezzacappa, P.A. Lasica, F. Gianfagna, O. Cazas, P. Hardy, B. Falissard, A.L. Sutter-Dallay, F. Gressier, Risk for autism spectrum disorders according to period of prenatal antidepressant exposure: a systematic review and meta-analysis, JAMA Pediatr. 171 (6) (2017) 555-563. 